\title{
PEMBINAAN ORGANISASI KELOMPOK USAHA MANDIRI MASYARAKAT (KUMM) BERBASIS AKUNTABILITAS DAN ISLAMI
}

\author{
Nurul Huda, Nazwirman, dan Hulmansyah \\ Program Magister Manajemen, Universitas Yarsi, Jakarta \\ Email: nurul.huda@yarsi.ac.id
}

\begin{abstract}
Sector Usaha Mikro Kecil dan mengengah (UMKM), in particular Micro is a business that is in desperate need of attention the government or society. Because there are huge numbers and can absorb a lot of labor. Community Service which is part of the efforts to develop micro approach to sharing and mentoring. The object of this Community Service is Business Usaha Mandiri Masyarakat (KUMM) are located in the districts of Tanjung Priok. Objective research provides knowledge and understanding of the entire board and management members on the basis of a business based on Islam and accountability. Mentoring to see the progress of the business. The result of activities carried out to make them satisfied and increased knowledge
\end{abstract}

Keywords: KUMM, Islam-based Management, Accountability, Mentoring

\section{PENDAHULUAN}

Undang-Undang No. 20 Tahun

2008 tentang Usaha Mikro, Kecil dan

Menengah Pasal 1 angka (1) menyebutkan: "Usaha Mikro adalah usaha produktif milik orang perorangan dan/atau badan usaha perorangan yang memenuhi kriteria Usaha Mikro sebagaimana diatur dalam UndangUndang ini." Pada Pasal 6 ayat (1) menyebutkan kriteria yang harus dipenuhi agar dapat disebut sebagai usaha mikro, yaitu:

1. Memiliki kekayaan bersih paling banyak Rp 50.000.000,00 (lima puluh juta rupiah) tidak termasuk tanah dan bangunan tempat usaha; atau
2. Memiliki hasil penjualan tahunan paling banyak $\mathrm{Rp}$ 300.000.000,00 (tiga ratus juta rupiah.

Pertumbuhan dan pengembangan Wirausaha Pemula merupakan salah satu solusi dalam menciptakan lapangan kerja, mengurangi pengangguran, meningkatkan produktifitas dan pendapatan masyarakat. Dalam upaya untuk mendukung Wirausaha Pemula meningkatkan kapasitas dan usahanya, Kementerian Koperasi dan UMKM menyalurkan bantuan permodalan bagi Wirausaha Pemula dalam bentuk modal awal yang diberikan secara selektif dan bervariasi antara Rp 5 juta hingga $R p 25$ juta. 
Program Bantuan Dana Bagi

Wirausaha Pemula Tahun 2015

ditargetkan diberikan kepada 3.560

wirausaha pemula dengan nilai anggaran Rp 89 Milyar. Dari alokasi tersebut, telah disalurkan bantuan dana kepada 8.362 Wirausaha Pemula Peserta Program dengan nilai Rp 88,47 Milyar,- atau sebesar $234,9 \%$ yang tersebar di 32 Provinsi.

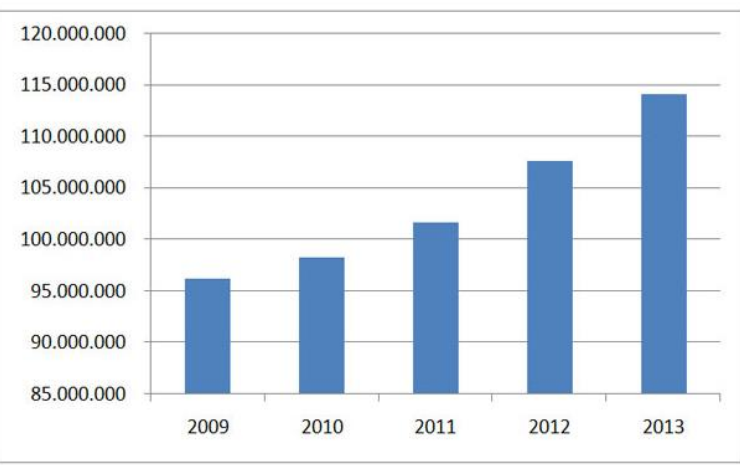

Sumber: Kementerian Koperasi dan UKM (2016)

Gambar 1. Grafik Penyerapan

\section{Tanaga Kerja UMKM 2009-2013}

Jumlah penyerapan tenaga kerja ke dalam bisnis UMKM cukup banyak atau meningkat dari tahun 2009 hingga tahun 2013 (Gambar 1). Jika dibandingkan dengan jenis UB (Usaha Besar), kontribusi UMKM jauh lebih besar jumlah penyerapan tenaga kerjanya.

Bila dipersentasekan jumlah kontribusi penyerapan tenaga kerja antara UMKM (Usaha Mikro, Kecil dan
Menengah) dengan UB (Usaha Besar), nampak seperti tabel di bawah ini:

Tabel 1. Data Presentase Penyerapan Tenaga Kerja UMKM dan UB

\begin{tabular}{|c|c|c|c|c|c|c|}
\hline № & Jenis Usaha & 2009 & 2010 & 2011 & 2012 & 2013 \\
\hline & Usaha Mikro, Kecil, dan Menengah & & & & & \\
1 & (UMKM) & 97,28 & 97,27 & 97,24 & 97,16 & 96,99 \\
\hline 2 & Usaha Besar (UB) & 2,72 & 2,73 & 2,76 & 2,84 & 3,01 \\
\hline
\end{tabular}
UKM (2016)

Berdasarkan Tabel 1 tahun 2009 sampai tahun 2013, jumlah penyerapan tenaga kerja untuk bisnis UMKM berada hampir 97 persen. Artinya keberadaan UMKM lebih mampu memberikan lowongan kerja kepada masyarakat Indonesia lebih besar, jika dibandingkan dengan Usaha Besar (UB).

Proses pemberdayaan mengandung dua kecenderungan yaitu kecendrungan pertama dimana proses pemberdayaan menekankan pada proses memberikan atau mengalihkan sebagian kekuatan, kekuasaan atau kemampuan kepada masyarakat agar individu lebih berdaya. Sedangkan kecenderungan kedua menekankan pada proses menstimulasi, mendorong atau memotivasi individu agar mempunyai kemampuan atau keberdayaan untuk menentukan apa yang menjadi pilihan hidupnya melalui proses dialog. Aliran ini menitik beratkan pada sikap dan 
pendapat yang berorientasi pada jargon antisistem, antistruktur, dan antideterminisme yang diaplikasikan pada dunia kekuasaan. Pemahaman konsep pemberdayaan oleh masingmasing individu secara selektif dan kritis dirasa penting, karena konsep ini mempunyai akar historis dari perkembangan alam pikiran masyarakat dan kebudayaan barat.

Pemberdayaan ekonomi di titik beratkan kepada para pelaku UMKM. Pemberdayaan UMKM biasanya adalah pengembangan sistem pendukung usaha KUMKM, Pengembangan kewirausahaan dan keunggulan kompetitif, Pemberdayaan usaha KUMKM, dan Peningkatan kualitas kelembagaan. Konsep pemberdayaan yang diaplikasi dalam studi-studi punya kecenderungan yang sama, yaitu sebagai upaya penguatan dan pembinaan sektor UMKM yang bersifat kelembagaan dan mencakup enam aspek: produksi, teknologi, pemasaran, manajerial, modal, dan kewirausahaan. Artinya, basis analisis konsep pemberdayaan selalu berdimensi ekonomi. UMKM perlu diberdayakan untuk menciptakan keunggulan dalam bersaing seperti menghasilkan produkproduk yang dapat memenuhi kebutuhan dan memuaskan keinginan konsumen (Anggara, 2015).

Akhir tahun 2015 UMKM akan menghadapi pasar bebas Asia tenggara atau di sebut MEA (Masyarakat Ekonomi Asean) yang mengharuskan semua pelaku UMKM memiliki kemampuan persaingan (competitive). Lingkungan bisnis yang kompetitif dan global pada belakangan ini menyebabkan UMKM harus benarbenar mampu bersaing dalam hal efisiensi, inovatif, penetapan harga, pengembangan usaha, dan lain-lain. Tingkat persaingan tersebut semakin tajam sejalan dengan semakin derasnya arus informasi, serta pesatnya perkembangan teknologi. Untuk dapat bertahan dalam arena persaingan, UMKM memerlukan strategi bersaing yang tepat. Suatu usaha akan dapat memenangkan persaingan apabila usaha tersebut memiliki keunggulan bersaing (competitive advantage). Kondisi inilah yang mendorong setiap pelaku UMKM berusaha untuk meningkatkan keunggulan bersaing.

Pelaku UMKM harus mampu bersaing satu sama lain dengan membuat sesuatu yang unik berorientasi pasar dan konsumen. Produk dari industri kreatif 
memerlukan strategi pemasaran yang baik tidak hanya dari industri tapi juga peran serta pemerintah sangat berpengaruh agar produk lokal industri kreatif kecil dan menengah dapat diminati tidak hanya warga lokal tapi juga warga negara asing. Namun perlu di waspadai oleh pengelola program pemberdayaan terkait dengan persaingan yang terjadi diantara pelaku UMKM. Pengelola program pemberdayaan harus mampu menciptakan akuntabilitas agar usaha tidak hanya sejehtera secara mandiri namun secara bersama-sama

Kelompok Usaha Mikro Mandiri (KUMM) salah satu keompok pemberdayaan masyarakat berada di wilayah kecamatan Tanjung Priok di beberapa kelurahan yaitu: KUMM AlKautsar-Sungai Bambu, KUMM An Najmu-Papanggo, KUMM Khoirussalam-Tanjung Priok dan KUMM Khairunnisa dan KUMM As Sakinah-Kebon Bawang di bawah pembinaan Yayasan Oase Anak Bangsa. Berdasarkan hasil survey awal yang dilakukan dapat diketahui bahwa KUMM ini adalah program Pemberdayaan Ekonomi dari Majelis Ta'lim. Jumlah pengurus sebanyak 3-5 orang dengan beranggotakan sebanyak $20-35$ orang.

Pelaku UMKM di KUMM Oase Anak Bangsa memproduksi olahan rumah tangga yang memproduksi antara lain pembuat kue-kue basah, nasi uduk, dan usaha yang dibutuhkan masyarakat sehari-hari. Secara fisik kondisi KUMM ini dalam pengelolaannya masingmasing menggunakan sekretariat Majelis Ta'lim, di mana aktivitas yang dilakukan adalah kegiatan pengajian rutin. Namun dalam kegiatannya, mereka masih kurang mampu membedakan mana modal usaha dan mana yang pribadi. Meraka masih tidak memeiliki catatan dari transaksi yang dilakukan setiap hari. Disamping itu mereka belum banyak memahami tentang berapa keuntungan usaha di diperbolehkan menurut ajaran Islam.

\section{Perumusan Masalah}

Minat yang tinggi Kelompok Usaha Mikro Mandiri (KUMM) ini berada di wilayah kecamatan Tanjung Priok untuk mengembangkan usaha anggota terhambat pada kendala teknis seperti pengelolaan dana usaha yang masih bercampur untuk dana kebutuhan sehari-hari, tentu hal ini harus diperbaiki. Hal ini menjadi tantangan sendiri untuk membantu pengelolaan 
usaha yang dilakukan tersebut dengan pendekatan akuntabilitas dan Islami. Pendekatan Islami digunakan karena anggota KUMM dominan anggota Majlis Tak'lim.

Perlunya pembinaan dan pendampingan kepada KUMM tentang membuka suatu usaha. Pembinaan dan pendampingan terhadap KUMM ini terkait dengan cara menemukan peluang yang baik, manajemen, keterampilan dalam mengelola usaha dan sebagainya agar permasalahan yang sering dihadapi oleh KUMM dapat berkurang ataupun teratasi.

\section{Tujuan Kegiatan}

Berdasarkan uraian dalam permasalahan maka tujuan dari kegiatan pengabdian kepada masyarakat ini yaitu

1. Memberikan pemahaman bagi Seluruh pengurus dan Anggota KUMM tentang dasar pengelolaan suatu usaha .

2. Memberikan Pemahaman bagi Seluruh pengurus dan Anggota KUMM tentang konsep Islam dalam mengelola usaha dan akuntabilitas usaha

3. Melakukan pendampingan untuk melihat kemajuan usaha yang dikelola

\section{KAJIAN TEORI}

Persoalan Dasar Usaha Mikro

Sasaran Strategis Kementerian Koperasi dan UKM untuk tahun 20152019 disusun berdasarkan dengan Tujuan yang akan diwujudkan Kementerian Koperasi dan UKM dalam lima tahun mendatang, serta dengan berpedoman pada sasaran nasional di bidang Koperasi dan UMKM yang dituangkan di dalam RPJMN 20152019, yaitu: (1) Meningkatnya kontribusi KUMKM dalam perekonomian melalui pengembangan komoditas berbasis koperasi/sentra di sektor-sektor unggulan;

Meningkatnya daya saing koperasi dan UMKM; (3) Meningkatnya wirausaha baru dengan usaha yang layak dan berkelanjutan; (4) Meningkatnya kualitas kelembagaan dan usaha koperasi, serta penerapan praktek berkoperasi dan yang baik oleh masyarakat.

Karakteristik utama UMKM adalah kemampuannya mengembangkan proses bisnis yang fleksibel dengan menanggung biaya yang relatif rendah (Warsono et al., 2010). Namun, salah satu tantangan utama yang dihadapi UMKM adalah terkait dengan pengelolaan dana. 
Ketidakberesan pengelolaan dana seringkali menjadi pemicu terjadinya kegagalan UMKM. Para pelaku UMKM memang perlu mendapatkan sosialisasi dan pembinaan baik secara finansial dan non finansial (Irawan, 2013). Inisiatif utama dalam pengelolaan dana adalah dengan mempraktikkan akuntansi dengan baik.

Pelaksanaan pembukuan akuntansi untuk menghasilkan laporan keuangan merupakan hal yang masih sulit bagi UMKM. Keterbatasan pengetahuan pembukuan akuntansi, rumitnya proses akuntansi, dan anggapan bahwa laporan keuangan bukanlah hal yang penting bagi UMKM menjadi alasan bagi UMKM untuk tidak melakukan pembukuan secara akuntansi. Banyak kasus-kasus para UMKM yang tidak melakukan pembukuan dengan benar atau bahkan tidak sama sekali, mengakibatkan mereka juga tidak mengetahui perkembangan usahanya (Murtiningtyas, 2013). Bahkan terkadang pencatatan yang dilakukan oleh UMKM hanya sebatas jumlah pembelian dan penjualan yang terjadi dalam kegiatan operasionalnya (Mutiah, Harwida dan Kurniawan, 2011). Terlebih lagi bentuk UMKM yang lebih didominasi perusahaan perseorangan mengakibatkan kurangnya kebutuhan untuk membuat laporan keuangan. Bentuk perusahaan perseorangan juga menyebabkan pemisahan keuangan bagi diri pribadi pemilik usaha dengan kegiatan usahanya seringkali juga tidak dilakukan.

\section{Akuntabilitas}

Menurut Ndraha (2003), konsep akuntabilitas berawal dari konsep pertanggungjawaban, konsep pertanggungjawaban sendiri dapat dijelaskan dari adanya wewenang. Wewenang di sini berarti kekuasaan yang sah. Menurut Weber ada tiga macam tipe ideal wewenang, Pertama wewenang tradisional, kedua wewenang karismatik dan ketiga wewenang legal rational. Ketigalah ini yang menjadi basis wewenang pemerintah. Dalam perkembanganya, muncul konsep baru tentang wewenang yang dikembangkan oleh Chester I. Barnard, yang bermuara pada prinsip bahwa penggunaan wewenang harus dapat dipertanggungjawabkan.

Menurut Fikri et al. (2010) lembaga Non Government Organization (NGO) memiliki banyak kelemahan terkait akuntabilitas, karena minimnya penyampaian informasi kepada 
masyarakat. Fikri et al. (2010) juga mengungkapkan bahwa rendahnya akuntabilitas NGO disebabkan, karena Interaksi antara NGO, donatur, dan masyarakat bukan semata murni hubungan ekonomi dan tidak selalu besifat formal (meskipun terkadang terdapat hubungan formal). Kepercayaan, emosi, kata hati, kontrak sosial, hubungan timbal balik, misalnya bercampur sehingga aturan formal untuk menentukan apakah organisasi akuntabel atau tidak sering kali menjadi bias. Riset yang dilakukan oleh Fikri et al. (2010) tersebut merupakan riset mengenai akuntabilitas NGO non keagamaan. Sementara, lembaga pengelola wakaf adalah NGO keagamaan

Randa et al. (2011) melakukan penelitian tentang akuntabilitas NGO keagamaan dalam sebuah gereja. Hasil penelitian Randa et al.(2011) menunjukkan bahwa akuntabilitas gereja berbeda dengan akuntabilitas NGO non kegamaan antara lain akuntabilitas spiritualitas. Riset Fikri $e t$ al. (2010) dan riset Randa et al. (2011) menunjukkan bahwa akuntabilitas NGO non keagamaan berbeda dengan NGO keagamaan yaitu pada sisi spiritualitas. NGO non keagamaan tidak memiliki akuntabilitas spiritualitas, sementara NGO keagamaan memiliki akuntabilitas spiritualitas.

\section{METODE PENELITIAN}

\section{Jenis Penelitian dan Rancangan} Penelitian

$\begin{array}{lcr}\text { Jenis } & \text { penelitian } & \text { adalah } \\ \text { penelitian } & \text { kuantitatif } & \text { dengan } \\ \text { menggunakan } & \text { instrumen } & \text { berupa } \\ \text { kuesioner dan pengukuran dengan skala } \\ \text { ordinal. Penelitian didesain sebagai } \\ \text { suatu survei yang merupakan jenis } \\ \text { kajian lapangan (field study) dan uji } \\ \text { Paired sample test dengan program } \\ \text { SPSS }\end{array}$

\section{Cara Penetapan dan Besar Sampel}

Populasi dalam penelitian adalah lima majelis taklim yang tergabung oleh Yayasan Oase Anak Bangsa Cabang Sungai Bambu Tanjung Priok.

Metode pengambilan sampel adalah dengan menggunakan metode purposive sampling. Dimana sampel diambil seluruh Jemaah majelis taklim yang hadir pada saat sosialisai, dan sebagian pelaku usaha KUMM.

\section{HASIL DAN PEMBAHASAN}

\section{Hasil Deskriptif Peserta}

Hasil pelaksanaan kegiatan

Pengabdian Kepada Masyarakat pada 
Oase Anak Bangsa di Tg. Priok menghasilkan.

a. Jenis Kelamin Peserta

Peserta kegiatan terdiri (Tabel 2) yaitu:

\section{Tabel 2. Jenis Kelamin Peserta}

\begin{tabular}{clll}
\hline No & Jenis Kelamin & Frekwensi & Persen \\
\hline $\mathbf{1}$ & Laki - laki & 0 & 0 \\
$\mathbf{2}$ & Perempuan & 33 & 100 \\
& Total & 33 & \\
\hline
\end{tabular}

Tabel 2 tampak bahwa jumlah peserta kegiatan sebanyak 33 orang. Dengan 33 orang seluruhnya atau 100 persen peserta adalah berjenis kelamin perempuan. Hal ini sangat dimungkinkan karena peserta seluruhnya seluruhnya ibu-ibu majelis taklim yang juga terlibat dala kegiatan kelompok usaha mandiri masyarakat.

b. Usia Peserta

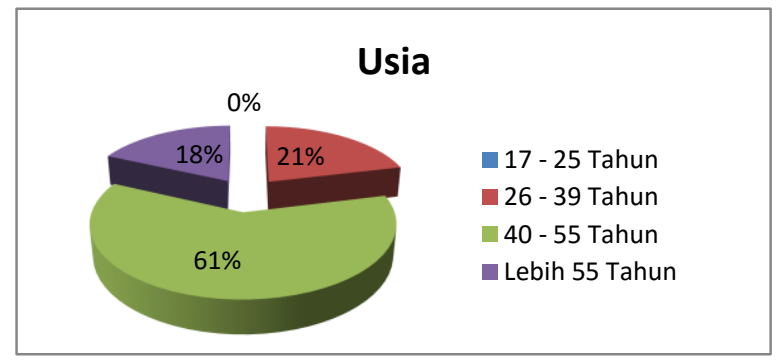

Gambar 1 Usia Peserta

Dari Gambar 1 tampak, usia peserta terdiri dari $61 \%$ atau 20 orang peserta berusia $40 \mathrm{~s} / \mathrm{d} 55$ tahun. $21 \%$ atau 7 orang peserta berusia 26 s/d 39 tahun, dan $18 \%$ atau 6 orang berusia lebih dari 55 tahun. Kecenderungan peserta merupakan single parent disebabkan kematian suami dan masyarakat menengah kebawah yang menopang penghasilan suami.

c. Pendidikan Peserta

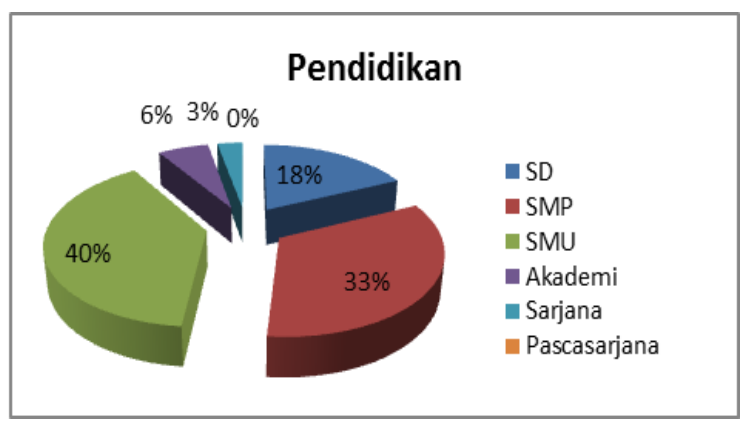

Gambar 2 Pendidikan Peserta

Dari Gambar 2 tampak, pendidikan peserta terdiri dari $40 \%$ atau 13 orang peserta berpendidikan SMU. 33\% atau 11 orang peserta berpendidikan SMP. 18\% atau 6 orang peserta berpendidikan SD. $6 \%$ atau 2 orang peserta berpendidikan Akademi. $3 \%$ atau 1 orang peserta berpendidikan Sarjana. Sebagain besar peserta lulusan SMU kebawah. Sehingga perlu pendampingan guna meningkatkan pengetahuan mereka.

d. Pekerjaan Peserta

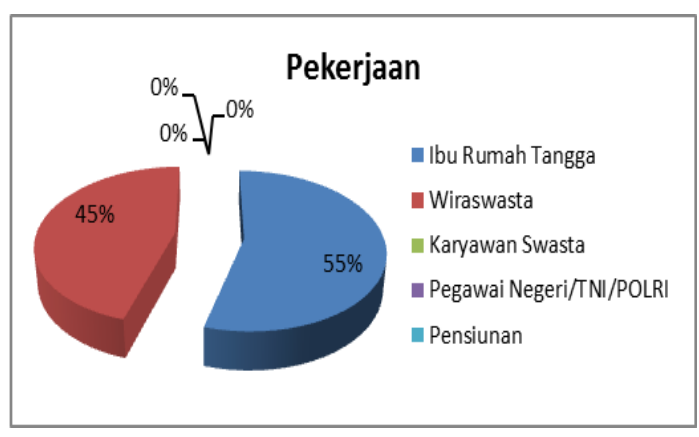

Gambar 3 Pekerjaan Peserta 
Dari Gambar 3 tampak, pekerjaan peserta terdiri dari $55 \%$ atau 18 orang peserta sebagai ibu rumah tangga. $45 \%$ atau 15 orang peserta berwirausaha. Sebagian peserta masih terlihat belum secara terbuka mengakui kegiatan mereka sebagai wirausaha. Mereka masih beranggapan usaha mereaka hanya sebatas membantu perekonomian suami.

\section{Tingkat Kepuasan Peserta}

Mengetahui tingkat kepuasan peserta dalam pelaksanaan pengabdian kepada masyarakat memberikan sebanyak 19 (sembilan belas) indikator pertanyaan yang terdiri dari 4 (empat dimensi) yaitu pembicara, materi, suasana, dan sarana/prasarana. Adapun hasilnya sebagai berikut:

a. Pembicara

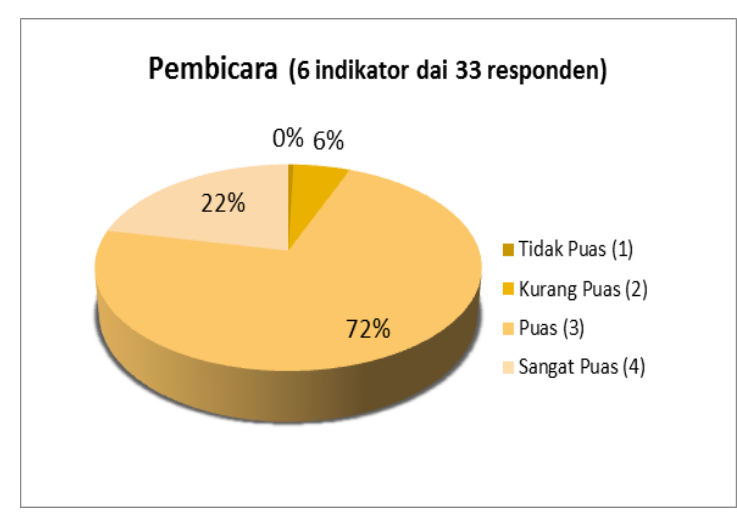

Gambar 4. Penilaian pembicara

\section{Pengabdian}

Dari Gambar 4 tampak, dari 33 peserta dengan 6 indikator pertanyaan sebanyak $72 \%$ peserta puas, $22 \%$ sangat puas, $6 \%$ kurang puas. Hal ini menunjukkan bahwa peserta puas dan antusias mengikuti kegiatan Pengabdian Kepada Masyarakat.

b. Materi Pelatihan

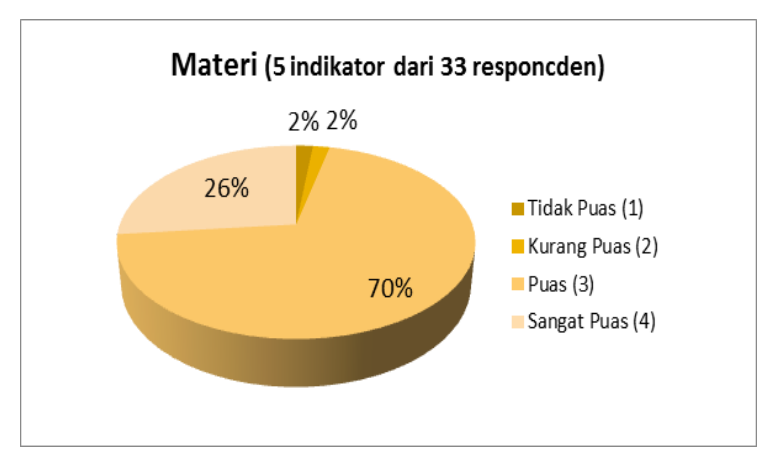

\section{Gambar 5. Penilaian Materi}

\section{Pelatihan}

Dari Gambar 5 tampak, dari 33 peserta dengan 6 indikator pertanyaan sebanyak $70 \%$ peserta puas, $26 \%$ sangat puas, $2 \%$ kurang puas, dan $2 \%$ tidak puas. Hal ini menunjukkan bahwa peserta puas dengan materi yang diberikan Pengabdian Kepada Masyarakat.

c. Suasana

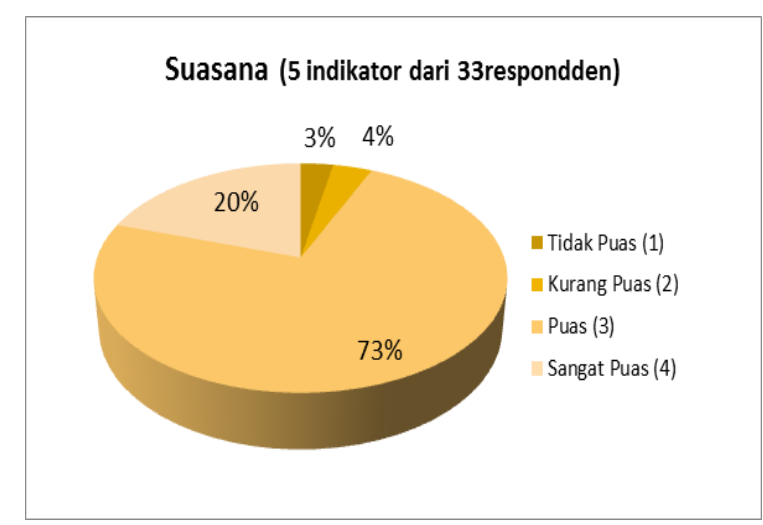

Gambar 6. Penilaian pembicara Pengabdian 
Dari Gambar 6 tampak, dari 33 peserta dengan 5 indikator pertanyaan sebanyak $73 \%$ peserta puas, $20 \%$ sangat puas, $4 \%$ kurang puas, dan 3\% tidak puas. Hal ini menunjukkan bahwa peserta puas dengan suasana lingkungan dalam pelaksanaan Pengabdian Kepada Masyarakat.

d. Sarana/Prasarana

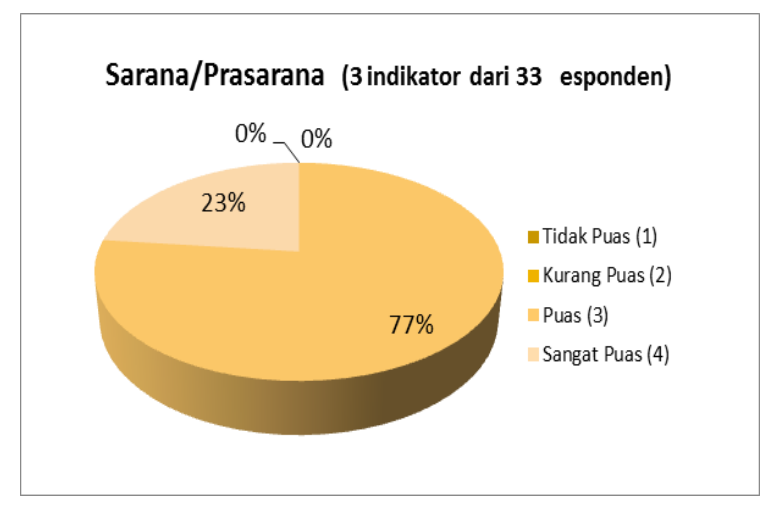

Gambar 7. Penilaian pembicara

\section{Pengabdian}

Dari Gambar 7 tampak, dari 33 peserta dengan 3 indikator pertanyaan sebanyak $77 \%$ peserta puas dan $23 \%$ sangat puas. Hal ini menunjukkan bahwa peserta puas dengan sarana/prasarana Pengabdian Kepada Masyarakat.

\section{Kemampuan Pre dan Post Test Peserta}

Mengetahui kemampuan peserta, pelaksanaan pengabdian kepada masyarakat memberikan sebanyak 6 (enam) butir pertanyaan yang menyangkut pengetahuan wirausahan berbasis Islam dan Akuntabilitas (Tabel 3.)

Tabel 3 . Deskrispi Data

Pretest dan Posttest

Paired Samples Statistics

\begin{tabular}{|ll|c|c|c|c|}
\hline & & & & $\begin{array}{c}\text { Std. } \\
\text { Deviation }\end{array}$ & $\begin{array}{c}\text { Std. } \\
\text { Error } \\
\text { Mean }\end{array}$ \\
\hline Pair 1 & Pretest & 3,1515 & 33 & 1,64167 &, 28578 \\
& Posttest & 5,3030 & 33 & 1,10354 &, 19210 \\
\hline
\end{tabular}

Dari Tabel 3 tampak, rata-rata (Mean) sebelum pemberian materi (pretest) sebesar 3,1515 dan setelah pemberian materi (posttest) sebesar 5,3030. Ini menunjukkan adanya penambambahan pengetahuan yang mereka ikuti.

Tabel 4. Paired sample correlation

Paired Samples Correlations

\begin{tabular}{|rl|r|r|r|}
\hline & $\mathrm{N}$ & $\begin{array}{c}\text { Correla } \\
\text { tion }\end{array}$ & Sig. \\
\hline Pair 1 & $\begin{array}{l}\text { Pretest } \\
\text { \& } \\
\text { Posttest }\end{array}$ & 33 &, 267 &, 133 \\
\hline
\end{tabular}

Dari Tabel 4 terlihat korelasi antara sebelum dan sesudah penyuluhan sebesar 0,267 atau $26,7 \%$ relatif korelasi rendah.

Tabel 5. Paired Samples Test

\begin{tabular}{|c|c|c|c|c|c|c|c|c|}
\hline & \multicolumn{5}{|c|}{ Paired Differences } & \multirow[b]{3}{*}{$t$} & \multirow[b]{3}{*}{ df } & \multirow[b]{3}{*}{ Sig. (2-tailed) } \\
\hline & \multirow[b]{2}{*}{ Nean } & \multirow[b]{2}{*}{ Std. Deviation } & \multirow{2}{*}{$\begin{array}{l}\text { Sto. Error } \\
\text { Mean }\end{array}$} & \multicolumn{2}{|c|}{$\begin{array}{l}\text { 95\% Conidence Interval of the } \\
\text { Difference }\end{array}$} & & & \\
\hline & & & & Lower & Upper & & & \\
\hline Pair1 Pretest-Postlest & $-2,15152$ & 1,71612 & 29874 & $-2,76003$ & $-1,54300$ & $.7,202$ & 32 &, 000 \\
\hline
\end{tabular}

Dari Tabel 5 terlihat nilai signifikansi

(2-tailed) $<0,05$, hal ini berarti

pemberian pelatihan memberikan

tambahan pengetahuan peserta. 


\section{KESIMPULAN}

Peserta kegiatan Pengabdian Kepada Masyarakat dihadiri seluruhnya berjenis kelamin perempuan, sebab anggotanya merupakan ibu-ibu beberpa majlis taklim dan anggota KUMM. Usia perserta lebih dominan berkisar anatara 40 s/d 55 tahun. Rata-rata pekerjaan mereka adalah ibu rumah tangga dan wirausaha. Mereka masih belum mengakui kegiatan mereka adalah wirausaha

Kamampuan pengetahuan peserta meningkat 36 persen dari sebelum kegiatan dilaksanakan. Tingkat kepuasan peserta dari aspek penilaian pembicara rata-rata jawaban puas. Tingkat kepuasan peserta dari aspek materi pelatihan rata-rata jawaban puas. Tingkat kepuasan peserta dari aspek suasana pelatihan rata-rata jawaban puas. Tingkat kepuasan peserta dari aspek sarana/prasarana rata-rata jawaban puas.

\section{DAFTAR PUSTAKA}

Anggara, Cici. 2015. Coopetition Usaha Mikro Kelompok Usaha Mandiri Mayarakat (KUMM) Desa Bantar Kambing. $\quad$ http://cici- anggara.co.id/2015/07/coop etition-usaha-mikrokelompok-usaha.html (Diunduh 12 Oktober 2016)

Fikri, A., M. Sudarma, E.G. Sukoharsono, dan B. Purnomosidhi. 2010. "Studi Fenomenologi Akuntabilitas Non Government Organization". Jurnal Akuntansi Multiparadigma, Vol. 1, No. 3, hlm 409-420.

Irawan, R. 2013. Aspek Perpajakan Usaha Mikro, Kecil dan Menengah. The 6th NCFB and Doctoral Colloquium, Unika Widya Mandala Surabaya.

Laporan tahunan Kementerian Koperasi dan Usaha Kecil dan Usaha Menengah, http://www.depkop.go.id/be rita-informasi/datainformasi/laporan-tahunan/ (Diunduh 21 Oktober 2016)

Murtiningtyas, T. 2013. Survei Pemahaman dan Kepatuhan Wajib Pajak (Studi pada UKM di Kelurahan Blimbing dan Lowokwaru Malang). The 6th NCFB and Doctoral Colloquium Unika Widya Mandala Surabaya.

Mutiah, M, G.A. Harwida dan F.A. Kurniawan. 2011. Interpretasi Pajak dan Implikasinya Menurut Perspektif Wajib Pajak Usaha Mikro, Kecil dan Menengah (Sebuah Studi Interpretif). Simposium Nasional Akuntansi (SNA)XIV Aceh.

Ndraha Taliziduhu, 2003, Kybernologi (Ilmu Pemerintahan Baru), Rineka Cipta, Jakarta, 
Randa, F., I. Triyuwono, U. Ludigdo, dan E.G. Sukoharsono. 2011. "Studi Etnografi: Akuntabilitas Sosial pada Organisasi Gereja Katolik yang Terinkulturasi Budaya Lokal". Jurnal Akuntansi Multiparadigma, Vol. 2, No. 1, hlm 35-51.
Undang-Undang No. 20 Tahun 2008 tentang Usaha Mikro, Kecil dan Menengah

Warsono, S., E. Murti, A.Ridha dan A.Darmawan. 2010. Akuntansi UMKM Ternyata Mudah Dipahami dan Dipraktikkan. Asgard Chapter. Yogyakarta. 